УДК 639.2 (913)

\title{
РЫБНЫЕ РЕСУРСЫ АРКТИЧЕСКИХ МОРЕЙ РОССИИ И ВОЗМОЖНОСТИ ИХ ЭКСПЛУАТАЦИИ
}

\author{
Балыкин П. А. \\ ФГБУН «ФИЦ Южный научный иентр РАН», г. Ростов-на-Дону \\ E-mail: balykin.pa@rambler.ru
}

\begin{abstract}
Приводятся сведения о современном рыболовстве и состоянии водных биоресурсов в арктических морях России. Сделан вывод об активном развитии рыбного промысла и аквакультуры в ближайшее десятилетие. Предлагается приступить к рыбохозяйственному районированию арктических морей России с применением методики морского пространственного планирования.
\end{abstract}

Ключевые слова: арктические моря России, рыболовство, аквакультура, морское пространственное планирование.

DOI: $10.34078 / 1814-0998-2021-1-101-107$

\section{ВВЕДЕНИЕ}

Все окружающие территорию России моря, кроме центральной и восточной Арктики, являются районами рыбного промысла. Рыбохозяйственная отрасль всегда занимала важное место в продовольственном обеспечении населения нашей страны. Наиболее динамичный период ее развития пришелся на 1980-е гг., когда годовой улов достигал 11.4 млн т и по этому показателю СССР поочередно делил первое место с Японией. Ежегодное потребление рыбной продукции на душу населения достигало 22-24 кг, что соответствует физиологическим нормам. Для сравнения сообщим, что в 2018 г. потребление рыбы в РФ было 17.2 кг на человека (https://fishnews.ru/ news/37201).

Регулирование и управление промышленным рыболовством осуществляется путем разделения акватории, находящейся под юрисдикцией государства или международной организации (таких, как Комиссия по рыболовству в Северо-Восточной Атлантике или Комиссия по рыболовству в Северо-Западной Атлантике), на участки, именуемые промысловыми районами. Федеральный закон «О рыболовстве и сохранении водных биологических ресурсов» от 20 декабря 2004 г. № 166-Ф3 содержит перечень рыбохозяйственных бассейнов: 1) Азово-Черноморский; 2) Байкальский; 3) Волжско-Каспийский; 4) Восточно-Сибирский; 5) Дальневосточный; 6) Западно-Сибирский; 7) Западный; 8) Северный (Комментарий..., 2005). Внутри каждого из выделенных бассейнов уста-

(C) Балыкин П. А., 2021 навливается деление на промысловые зоны и подзоны. Например, схема рыбопромыслового районирования Баренцева моря была разработана в 1974 г. главком «Севрыба», а схема рыбопромыслового районирования Дальневосточного бассейна утверждена приказом МРХ СССР в 1989 г. (Варкентин, Сергеева, 2017).

По предварительной оценке (https://fishnews. $\mathrm{ru} /$ news/38316), в 2019 г. российскими рыбаками было добыто 4.92 млн т рыбы и морепродуктов, что несколько меньше, чем в 2018 г. (5.04 млн т). Как и в предыдущие годы, основная доля вылова пришлась на Дальневосточный бассейн 3.42 млн т, или более $69 \%$ суммарного улова. На втором месте - Северный бассейн: 0.49 млн т, или около $10 \%$ общего улова. В зонах иностранных государств, конвенционных районах и открытой части Мирового океана российский рыбопромысловый флот выловил 0.72 млн т рыбы и других биоресурсов, т. е. свыше $14 \%$ суммарной добычи. Западный, Азово-Черноморский и ВолгоКаспийский бассейны внесли небольшой вклад в величину улова за 2019 г. Таким образом, более $85 \%$ водных биоресурсов добывается в пределах 200 -мильной экономической зоны России, причем большая часть сосредоточена в северных и дальневосточных морях. Вклад арктических акваторий в российское рыболовство может существенно возрасти в ближайшие годы вследствие развития процессов глобального потепления. Повышение температуры окружающей среды в Арктике происходит более чем в 2.5 раза быстрее, чем в среднем на Земле (Второй..., 2014). Ожидается, что к середине XXI в. Северный Ледовитый океан летом будет полностью свободным от 
толстого многолетнего льда. Согласно прогнозу британских и американских специалистов, летний морской лед в арктических морях может исчезнуть в 2030-х гг. (Bjornes, Prestrud, 2012; https://www.eurekalert.org/pub_releases/2019-02/ agu-ias022719.php). Наша страна должна быть была готова к ожидаемому освобождению арктических акваторий ото льда и расширению, в связи с этим, рыбохозяйственной деятельности в морях Северного Ледовитого океана. Цель настоящей работы - обобщение доступных автору данных о величине и составе уловов, состоянии водных биоресурсов арктических морей как основы для разработки предложений по дальнейшим мерам развития рыболовства и аквакультуры.

\section{РЕЗУЛЬТАТЫ И ОБСУЖДЕНИЕ}

Арктическая зона РФ занимает около 7 млн км ${ }^{2}$ водного пространства, что превышает 50\% площади Северного Ледовитого океана. Также к арктическим акваториям относится часть российского сектора Берингова моря (к северу от 64 с. ш.), являющегося частью Пацифики (Добровольский, Залогин, 1982). Она невелика по размерам и включает воды вдоль Чукотского побережья вплоть до границы между акваториями российской и американской юрисдикции. В качестве отдельного промыслового района (зона Чукотская) эта акватория выделяется с 2008 г., до этого она была частью зоны Западноберинговоморская (Антонов и др., 2016).

Рыбный промысел в российской Арктике осуществляется в Баренцевом, Беринговом и, в

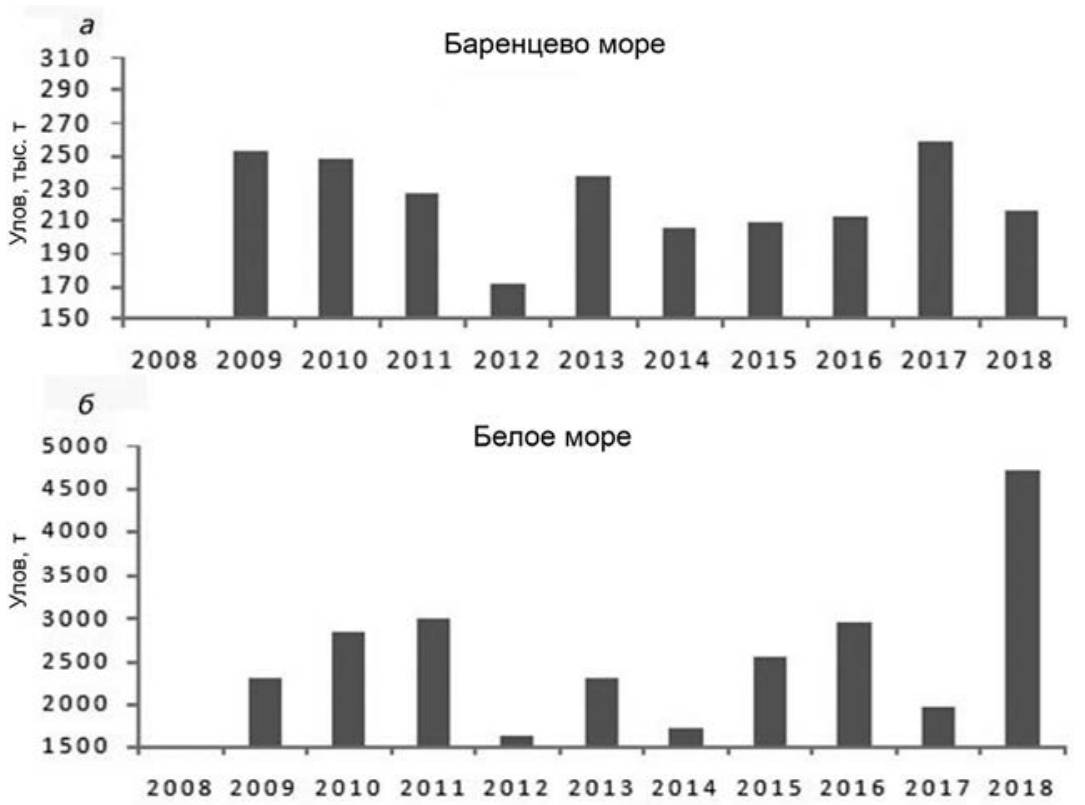

Puc. 1. Российские уловы в Баренцевом (a) и Белом (б) морях в 20092018 гг. 2018 меньшем объеме, в Белом море, тогда как Карское, Восточно-Сибирское, Чукотское и море Лаптевых нельзя назвать районами регулярного рыболовства.

Число видов рыб, обитающих в Баренцевом море (222 вида), сравнимо с составом ихтиофауны других районов Северной Атлантики и превышает их количество в арктических морях России: в Белом море - 67 видов рыб, из них 15 - пресноводных, в Карском море 70 видов (10 - пресноводных), в море Лаптевых - не свыше 40 (Долгов, 2012). В бассейне Восточно-Сибирского моря в настоящее время известны 33, а с учетом пресноводных 69 представителей ихтиофауны (Кириллов и др., 2016). Восточно-Сибирское море по данному параметру значительно уступает расположенному восточнее Чукотскому морю (112 видов), где высока доля арктическо-бореальных и бореальных видов, проникающих через Берингов пролив (http://www.tinro- center.ru/home/novosti/ specialisty tinro oznakomili kolleg s dostizeniami i planami issledovanij).

Согласно информации с официального сайта Росрыболовства (http://fish.gov.ru/otraslevayadeyatelnost/organizatsiya-rybolovstva/osvoenierekomendovannykh-ob-emov-vylova), в 2009 2018 гг. в Баренцевом море российскими рыбаками вылавливалось от 171.3 (2012) до 258.4 (2017) тыс. т водных биоресурсов. При этом следует обратить внимание на то, что в акватории Баренцева моря наиболее продуктивные районы промысла находятся в экономической зоне Норвегии, где в среднем добывается в 3 раза больше рыбы, чем в российской (Рыбаков и др., 2011). В Белом море добыча на два порядка меньше - от 1.6 (2012) до 4.7 (2018) тыс. т (рис. 1).

В северной части Берингова моря уловы изменялись от 0.6 (2009) до 12 (2017) тыс. т (рис. 2).

Вышеуказанный источник сообщает об уловах в Карском море в некоторые годы (2010, $2017,2018)$ от 0.2 до 0.6 тыс. т, а в 2013 и 2016 г. добыча составляла 4 и 48 т соответственно. Для Чукотского моря отчетные данные Росрыболовства указывают вылов от 1 (2012) до 80 (2017) т водных биоресурсов. Для моря Лаптевых в 2015 г. приводится величина улова в 10 т, в Восточно-Сибирском море рыбного промысла не было. 
В данных документах Росрыболовства приводится и видовой состав уловов. Известно, что в Баренцевом море основными промысловыми видами являются такие донные рыбы, как треска, пикша, зубатка, морской окунь, черный палтус, морская камбала, камбала-ерш, и пелагические - мойва и сайка (Жичкин, 2014). В Белом море издавна добывали сельдь, нава-

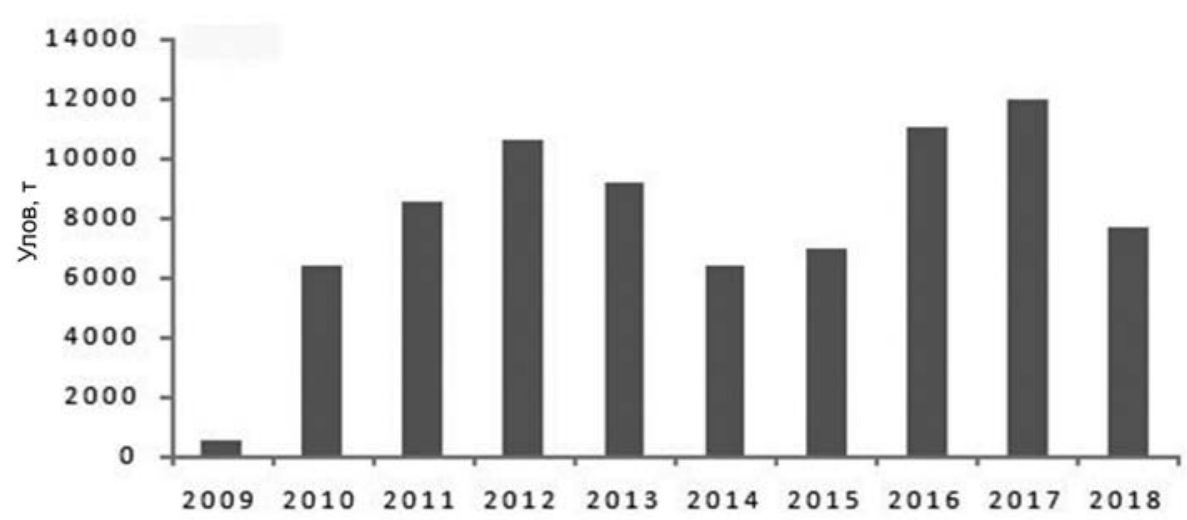

Puc. 2. Российские уловы в зоне Чукотская в 2009-2018 гг.

Fig. 2. Russian catches in the Chukotka zone, 2009-2018 гу, семгу и морских млекопитающих. Современный состав уловов в Белом море показан на рис. 3.

Кроме указанных на рис. 3 видов рыб, в промысловой отчетности наличествуют также уловы зубатки, трески, сига, корюшки, речного окуня и моллюска морского гребешка в количестве 1-6 т.

В зоне Чукотская в 2017-2020 гг. уловы наполовину состояли из минтая и трески, было добыто также по 2 т белокорого палтуса и нерки. Для Чукотского моря в качестве промысловых объектов указываются налим, голец и морские млекопитающие. Основная часть улова изымается при промысле гольцов в опресненных участках рек, впадающих в море (Датский, 2019). Более разнообразен видовой состав уловов в Карском море (рис. 4). Здесь отмечены рыбы 10 видов, преимущественно сиговые (сиг, чир, муксун, омуль, пелядь, ряпушка, корюшка) - около 80\%, а также налим, ерш и язь.

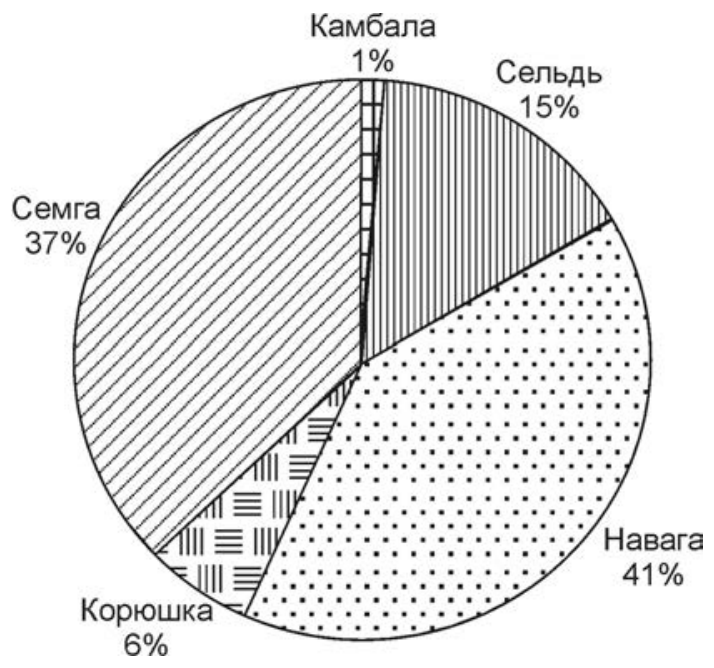

Рuc. 3. Видовой состав уловов в Белом море в 2017-2020 гг.

Fig. 3. Species composition of catches in the White Sea, 2017-2020
Известно, что промысловая отчетность не дает полного представления об объемах реального изъятия водных биоресурсов, так как не учитывается воздействие незаконного промысла (Балыкин, 2011; Балыкин, Болтнев, 2014). Поэтому для оценки возможностей рыбопромысловой эксплуатации арктических морей России следует обратиться к результатам научных исследований.

Наиболее исследованным районом можно назвать море Лаптевых, где в разные годы проводилось множество экспедиций, в том числе и в рамках международных проектов. Исследования на полигоне в море Лаптевых в 2015 г. показали наличие скоплений сайки на внешней части шельфа и материковом склоне (Глебов и др., 2016).

Из перечисленных морей наиболее богато промысловыми водными биоресурсами, несомненно, Чукотское. Самым высокопродуктивным районом в российской части Чукотского моря является его юго-западная часть между

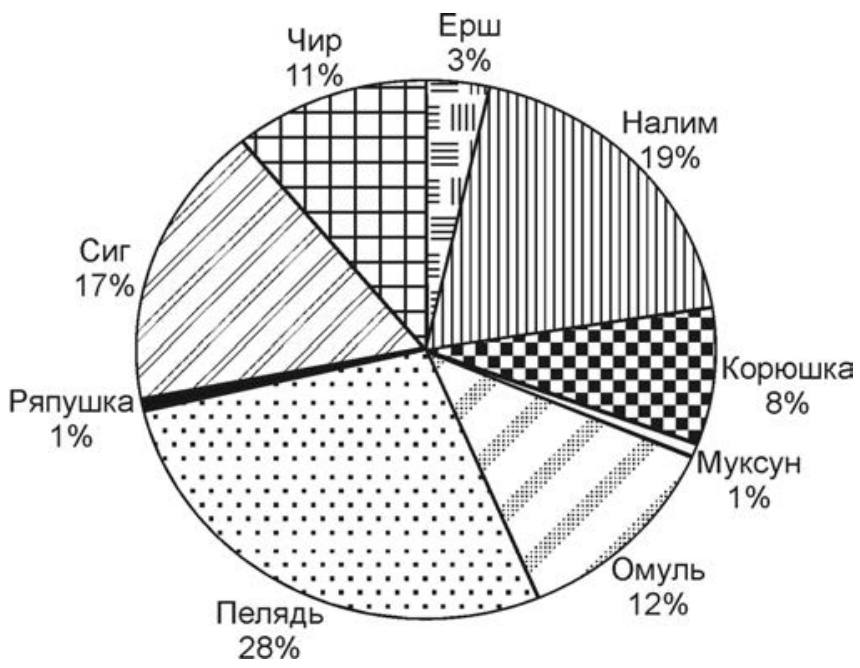

Puc. 4. Видовой состав уловов в Карском море в 20172020 гг.

Fig. 4. Species composition of catches in the Kara Sea, 2017- 
о. Врангеля и Беринговым проливом. Из 30 встречающихся в траловых уловах видов рыб наиболее массовая - сайка. Однако она склонна к резким изменениям численности. Выполненные в начале 2000-х гг. съемки в Беринговом и Чукотском морях показали, что численность этой рыбы находилась на достаточно высоком уровне. Но в последующие годы отмечалось заметное снижение количества сайки. Тем не менее это рыбный объект, способный формировать промысловые скопления.

Кроме сайки, в Чукотском море можно отметить еще мойву, сельдь и несколько видов лососей (кета, нерка, чавыча). Численность этих рыб в пределах исследованных акваторий не высока, однако они могут представлять интерес для местного населения.

Помимо рыб, промысловое значение в Чукотском море могут иметь еще ракообразные и моллюски. В ходе экспедиций там встречались плотные скопления краба-стригуна опилио. Кроме того, в прошлые годы отмечался высокий уровень численности других видов донных беспозвоночных - креветок, брюхоногих и двустворчатых моллюсков. Также исследователи неоднократно замечали, что в последние годы в Чукотском море стало гораздо больше рыб, проникающих в летний период из Берингова моря (http://www. rybazdes.ru/node/7334).

В 2019 г. была осуществлена самая масштабная на сегодня трансарктическая экспедиция на научно-исследовательском судне «Профессор Леванидов», в ходе которой были обследованы акватории арктических морей от г. Анадыря до г. Мурманска. Отмечен значительный рост численности промысловых рыб в Чукотском море. По предварительным оценкам, количество минтая по сравнению со съемкой 2018 г. возросло более чем в 50 раз. Биомасса крупного минтая составила 890 тыс. т, сайки - 117 тыс. т, палтусовидной камбалы - 42 тыс. т (Орлов и др., 2019). Оконтурена восточная граница ареала крабастригуна опилио в Восточно-Сибирском море. Показано, что это море является на сегодня наименее перспективным в рыбохозяйственном отношении из всех арктических морей России. В море Лаптевых концентрации черного палтуса обнаружены практически на протяжении всего материкового склона. В Карском море отмечено широкое расселение краба-стригуна опилио по всей акватории моря. Численность сайки в Карском море в сравнении с предшествующей съемкой 2013 г. существенно возросла, вероятно, по причине перераспределения из Баренцева моря в результате климатических перестроек (http://vniro.ru/ru/novosti/vo-vniro-sostoyalosrasshirennoe-zasedanie-uchenogo-soveta). В ходе работ были обнаружены несколько видов рыб за пределами их известных ареалов. Это минтай, синяя зубатка и окунь-клювач, которых раньше в море Лаптевых не ловили. Исходя из полученных результатов, предложено установить общий допустимый улов (ОДУ) краба-стригуна опилио в Карском море и минтая - в Чукотском, значительно увеличены допустимые уловы минтая и трески в зоне Чукотская в 2020-2021 гг. (https://fishnews.ru/news/38678, https://fishnews. $\mathrm{ru} /$ news/38701).

Указ Президента РФ об основах государственной политики России в Арктике до 2035 г. предусматривает развитие рыболовства, рыбопереработки и аквакультуры, поэтому, кроме промышленного рыболовства, Минвостокразвития совместно с регионами готовит перечень мер для развития аквакультуры в арктической зоне России. При этом учитывается, что тема развития рыбоводства в большей степени актуальна для Карелии, Мурманской и Архангельской областей как наиболее населенных арктических регионов.

Таким образом, полученные в научных экспедициях результаты дают основание предварительно заключить, что биологические ресурсы арктических морей позволяют не только обеспечить стабильный промысел для нужд местного населения, но и вести экспедиционный лов некоторых гидробионтов. Для рационального использования водных биоресурсов следует составить схемы рыбохозяйственного районирования арктических морей на базе современных научных знаний о границах морских экосистем и популяционном составе промысловых гидробионтов. Как показал опыт Норвегии, товарная аквакультура вполне успешна в условиях арктических морей. Поэтому, кроме выделения зон под промышленное рыболовство, схема рыбохозяйственного районирования должна включать участки для развития аквакультурного производства.

Практика морской хозяйственной деятельности позволяет назвать рыбный промысел и морской транспорт как самых значимых в социальном, экономическом и экологическом аспектах отрасли. На эту основу использования природных ресурсов накладываются другие виды антропогенного воздействия: разработка месторождений и транспорт углеводородного сырья, переработка газоконденсата, марикультура, рекреационная деятельность, создание природоохранных зон. Очевидно, что морехозяйственная деятельность в морях российской Арктики должна планироваться в рамках комплексных программ с применением современных методических подходов. Канада, США и Норвегия уже разработали планы интегрированного управления деятельностью на морях, находящихся под их юрисдикцией (Ba- 
сильев, Куранов, 2010). В качестве инструмента осуществления морской политики экономически развитые страны используют в настоящее время морское пространственное планирование (МПП), основанное на экосистемном подходе к управлению морской деятельностью (Васильев, 2013). Знакомство с методологией МПП демонстрирует, что его основная задача - создать условия для плодотворной деятельности различных хозяйственных отраслей, включая рыболовство, нефтегазовую промышленность и морской транспорт (Мякиненков, 2013). Опыт приложения методики морского пространственного планирования для решения хозяйственных задач в Арктике имеется в учреждениях РАН, например, в Мурманском морском биологическом институте (ММБИ). Учеными ММБИ осуществлены исследования в целях зонирования Баренцево-Карского морского региона для разработки стратегического плана интегрированного природопользования (http://barenzevo.arktikfish. com/index.php/ekonomika/200-funktsionalnoezonirovanie-barentseva-i-karskogo-more). Аналогичный план для норвежского сектора Баренцева моря был разработан и одобрен Стортингом (парламентом) Норвегии в 2007 г. (Денисов, Ильин, 2008).

\section{ЗАКЛЮЧЕНИЕ}

Чтобы Российская Федерация была готова к началу хозяйственной деятельности в морях Арктики в случае освобождения их ото льда, следует уже сейчас начать активную подготовку. В качестве первого этапа предлагается осуществить рыбохозяйственное районирование морских акваторий с учетом освоения нефтяных и газовых месторождений и интересов Севморпути. Эта работа может быть выполнена институтами РАН в сотрудничестве с учреждениями Росрыболовства, Минприроды и другими региональными НИИ.

\section{ЛИТЕРАТУРА}

Антонов Н. П., Кловач Н. В., Орлов А. М., Датский А. В., Лепская В. А., Кузнецов В. В., Яржомбек А. А., Абрамов А. А., Алексеев Д. О., Моисеев С. И., Евсеева Н. А., Сологуб Д. О. Рыболовство в Дальневосточном рыбохозяйственном бассейне в 2013 г. // Труды ВНИPO. 2016. T. 160. C. 133-211.

Балькин П. А. Насущные вопросы российского рыболовства // Известия ТИНРО. Владивосток. 2011. T. 165 . C. $56-64$.

Балькин П. А., Болтнев А. И. Актуальные проблемы сохранения и использования водных биоресурсов // Использование и охрана природных ресурсов России. 2014. № 1. С. 35-39.

Варкентин А. И., Сергеева Н. П. Промысел минтая (Theragra halcogramma) в прикамчатских водах в 2003-2015 гг. // Исследования водных биологиче- ских ресурсов Камчатки и северо-западной части Тихого океана. Петропавловск-Камчатский. 2017. Вып. 47. C. 5-45. DOI: 10.15853/2072-8212.2017.47. $5-45$

Васильев А. М. Комплексный подход к организации морехозяйственной деятельности в Западной Арктике // Экономические и социальные перемены: факты, тенденции, прогноз. 2013. № 1 (25). С. 5665.

Васильев А. М., Куранов Ю. Ф. Проблемы освоения биологических ресурсов Арктических морей // Вестник МГТУ. 2010. Т. 13, № 4/1. С. 686-694.

Второй оценочный доклад Росгидромета об изменениях климата и их последствиях на территории Российской Федерации. Общее резюме. Москва : Росгидромет, 2014. $61 \mathrm{c.}$

Глебов И. И., Надточий В. А., Савин А. Б., Слабинский А. М., Борилко О. Ю., Чульчеков Д. Н., Соколов $A$. $C$. Результаты комплексных биологических исследований в море Лаптевых в августе-сентябре 2015 г. // Известия ТИНРО. Владивосток. 2016. Т. 187. C. $72-88$.

Датский А. В. Сырьевая база рыболовства и ее использование в российских водах Берингова моря. Сообщение 1. Суммарный прогнозируемый и фактический вылов водных биологических ресурсов за период с 2000 по 2015 г. // Труды ВНИРО. 2019. Т. 175. C. $130-152$.

Денисов В. В., Ильин Г. В. Районирование акваторий как инструмент оптимизации природопользования на арктическом шельфе // Проблемы Арктики и Антарктики. 2008. № 2 (79). С. 134-144.

Добровольский А. Д., Залогин Б. С. Моря СССР. Москва : Изд-во МГУ, 1982. 192 с.

Долгов A. В. Состав, формирование и трофическая структура ихтиоцена Баренцева моря : автореф. дис. ... д-ра биол. наук. Москва, 2012. 48 с.

Жичкин А. П. Пространственно-временная изменчивость промысловой значимости различных районов рыбного лова в Баренцевом море // Вестник МГТУ. 2014. T. 17, № 3. С. 465-473.

Кириллов А. Ф., Апсолихова О. Д., Жирков Ф. Н., Карпова Л. Н., Свешников Ю. А., Бурмистров Е. В. Аннотированный список рыбообразных и рыб бассейна Восточно-Сибирского моря // Исследования водных биологических ресурсов Камчатки и северо-западной части Тихого океана. Петропавловск-Камчатский, 2016. Вып. 42. С. 78-87. DOI 10.15853/2072-8212.2016. 42.78-87

Комментарий к Федеральному закону «О рыболовстве и сохранении водных биологических ресурсов» (постатейный). Москва : ЗАО «Юстицинформ», 2005. 192 c.

Мякиненков В. М. Основные подходы к формированию инструментария и методические особенности морского пространственного планирования // Региональное развитие и пространственное планирование территорий. Санкт-Петербург : Изд-во СПГУ, 2013. C. 99-115.

Орлов А. М., Бензик А. Н., Ведищева Е. В., Гафиикий С. В., Горбатенко К. М., Горянина С. В., Зубаревич В. Л., Кодрян К. В., Носов М. А., Орлова С. Ю., 
Педченко А. П., Рыбаков М. О., Соколов А. М., Сомов А. А., Субботин С. Н., Таптыгин М. Ю., Фирсов Ю. Л., Хлебородов А. С., Чикилев В. Г. Рыбохозяйственные исследования в Чукотском море на НИС «Профессор Леванидов» в августе 2019 г.: некоторые предварительные результаты // Труды ВНИРО. 2019. T. 178. С. 206-220.
Рыбаков Ф. Ф., Агарков С. А., Бреславеи И. Н. Региональные особенности экономического развития рыболовства Северного бассейна // Вестник МГТУ. 2011. T. 14, № 1. C. 74-78.

Bjornes C., Prestrud P. The state of the poles: Climate lessons from the International Polar Year. Oslo : Akademika Unipub Publishing, 2012. P. 27.

Поступила в редакичю 24.03.2020 2.

Поступила после доработки 11.09.2020 2.

\title{
FISH RESOURCES OF RUSSIA'S ARCTIC SEAS AND OPPORTUNITIES FOR THEIR EXPLOITATION
}

\author{
P. A. Balykin
}

\author{
Southern Scientific Center of the Russian Academy of Sciences, Rostov-on-Don
}

\begin{abstract}
The article provides information on modern fishery and the state of aquatic bioresources in the seas of Russia's Arctic. The conclusion is made about the active development of fishery and aquaculture in the nearest decade. It is proposed to start fishery zoning of Russia's Arctic seas using the methodology of marine spatial planning.
\end{abstract}

Keywords: Russia's Arctic seas, fishery, aquaculture, marine spatial planning.

\section{REFERENCES}

Antonov, N. P., Klovach, N. V., Orlov, A. M., Datsky, A. V., Lepskaya, V. A., Kuznetsov, V. V., Yarzhombek, A. A., Abramov, A. A., Alekseyev, D. O., Moiseyev, S. I., Yevseye$v a$, N. A., Sologub, D. O., 2016. Fishing in the Far Eastern Fishery Basin in 2013, Trudy VNIRO. 160, 133-211 [In Russian].

Balykin, P. A., 2011. Pressing Issues of the Russian Fisheries, Izvestiya TINRO. Vladivostok. 165, 56-64 [In Russian].

Balykin, P. A., Boltnev, A. I., 2014. Current Problems of Conservation and Use of Aquatic Bioresources, Use and Protection of Natural Resources of Russia. 1, 35-39 [In Russian].

Bjornes, C., Prestrud, P., 2012. The State of the Poles: Climate Lessons from the International Polar Year. Oslo, Akademika Unipub Publishing. 27.

Commentary to the Federal Law "On Fishing and Conservation of Aquatic Biological Resources" (Articleby-Article), 2005. Moscow [In Russian].

Datsky, A., 2019. Fishery Resource Base and Its Use in the Russian Waters of the Bering Sea, Presentation 1, Total Predicted and Actual Catch of Aquatic Biological Resources for the Period 2000 to 2015, Trudy VNIRO. 175, 130-152 [In Russian].

Denisov, V. V., Ilyin, G. V., 2008. Zoning of Water Areas as a Tool for Optimizing Environmental Management on the Arctic Shelf, Arctic and Antarctic Research. 2 (79), 134-144 [In Russian].

Dobrovol'sky, A. D., Zalogin, B. S., 1982. Seas of the USSR. Moscow, MSU [In Russian].

Dolgov, A. V., 2012. Composition, Formation, and Trophic Structure of the Barents Sea Ichthyocene, Avtoref. Diss. Doktora Biol. Nauk. Moscow [In Russian].
Glebov, I. I., Nadtochiy, V. A., Savin, A. B., Slabinsky, A. M., Borilko, O. Ju., Chul'chekov, D. N., Sokolov, A. S., 2016. Results of Multi-Disciplinary Biological Research in the Laptev Sea in August-September, 2015, Izvestiya TINRO. Vladivostok. 187, 72-88 [In Russian].

Kirillov, A. F., Apsolikhova, O. D., Zhirkov, F. N., Karpova, L. N., Sveshnikov, Ju. A., Burmistrov E. V., 2016. Annotated List of Lampreys and Fishes of the East Siberian Sea Basin, The Researches of the Aquatic Biological Resources of Kamchatka and the North-West Part of the Pacific Ocean. 42, 78-87. DOI 10.15853/2072-8212. 2016.42.78-87 [In Russian].

Myakinenkov, V. M., 2013. Main Approaches to the Formation of Tools and Methodological Features of Marine Spatial Planning, Regional Development and Spatial Planning of Territories. St. Petersburg, SPGU. 99-115 [In Russian].

Orlov, A. M., Benzik, A. N., Vedishcheva, E. V., Gafitsky, S. V., Gorbatenko, K. M., Goryanina, S. V., Zubarevich, V. L., Kodryan, K. V., Nosov, M. A., Orlova, S. Ju., Pedchenko, A. P., Rybakov, M. O., Sokolov, A. M., Somov, A. A., Subbotin, S. N., Taptygin, M. Ju., Firsov, Ju. L., Khleborodov, A. S., Chikilev, V. G., 2019. Fisheries Research in the Chukchi Sea on the RV "Professor Levanidov" in August 2019: Some Preliminary Results, Trudy VNIRO. 178, 206-220 [In Russian].

Rybakov, F. F., Agarkov, S. A., Breslavets, I. N., 2011. Regional Features of the Economic Development of Fishing in the Northern Basin, Vestnik MSTU. 14, 1, 74-78 [In Russian].

Second Assessment Report of Rosgidromet on Climate Change and Its Consequences on the Territory of the 
Russian Federation, General Summary, 2014, Moscow, Rosgidromet [In Russian].

Varkentin, A. I., Sergeeva, N. P., 2017. Walleye Pollock (Theragra chalcogramma) Fishery in the Kamchatka Peninsula Waters in 2003-2015, The Researches of the Aquatic Biological Resources of Kamchatka and the North-West Part of the Pacific Ocean, 47, 5-45. DOI: 10.15853/2072-8212.2017.47.5-45 [In Russian].

Vasilyev, A. M., 2013. Integrated Approach to the Organization of Marine Activities in the Western Arctic,
Economic and Social Changes: Facts, Trends, Forecast. 1 (25), 56-65 [In Russian].

Vasilyev, A. M., Kuranov, Ju. F., 2010. Problems of Exploring Biological Resources of the Arctic Seas, Vestnik of MSTU. 13, 4/1, 686-694 [In Russian].

Zhichkin, A. P., 2014. Space-Time Variability of Commercial Significance of Different Fishing Areas in the Barents Sea, Vestnik of MSTU. 17, 3, 465-473 [In Russian]. 